\title{
Downregulated PITX1 Modulated by MiR- 19a-3p Promotes Cell Malignancy and Predicts a Poor Prognosis of Gastric Cancer by Affecting Transcriptionally Activated PDCD5
}

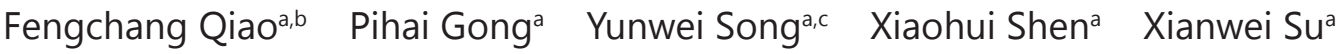 \\ Yiping $\mathrm{Li}^{\mathrm{d}}$ Huazhang Wu $\mathrm{W}^{\mathrm{a}}$ Zhujiang Zhao ${ }^{\mathrm{a}}$ Hong Fan $^{\mathrm{a}}$
}

\begin{abstract}
aDepartment of Medical Genetics and Developmental Biology, Medical School of Southeast University, The Key Laboratory of Developmental Genes and Human Diseases, Ministry of Education, Southeast University, Nanjing, 'Department of Prenatal Diagnosis, the Affiliated Obstetrics and Gynecology Hospital of Nanjing Medical University, Nanjing Maternity and Child Health Care Hospital, Nanjing, cHospital of Integration of Chinese and Western Medicine, Affiliated with Nanjing University of Chinese Medicine, Nanjing, dDepartment of Pathology, Medical school of Southeast University, Nanjing, China
\end{abstract}

\section{Key Words}

Pitx1 • PDCD5 • Cell proliferation • Cell apoptosis $・$ MiR-19a-3p

\begin{abstract}
Background/Aims: PITX1 has been identified as a potential tumor-suppressor gene in several malignant tumors. The molecular mechanism underlying PITX1, particularly its function as a transcription factor regulating gene expression during tumorigenesis, is still poorly understood. Methods: The expression level and location of PITX1 were determined by quantitative reverse transcription PCR (qRT-PCR) and immunohistochemical staining in gastric cancer (GC). The effect of PITX1 on the GC cell proliferation and tumorigenesis was analyzed in vitro and in vivo. To explore how PITX1 suppresses cell proliferation, we used PITX1-ChIP-sequencing to measure genome-wide binding sites of PITX1 and assessed global function associations based on its putative target genes. ChIP-PCR, electrophoretic mobility shift assay, and promoter reporter assays examined whether PITX1 bound to PDCD5 and regulated its expression. The function of PDCD5 in GC cell apoptosis was further examined in vitro and in vivo. The relationship between the PITX1 protein level and GC patient prognosis was evaluated by the Kaplan-Meier estimator. Meanwhile, the expression level of miR-19a-3p, which is related to PITX1, was also detected by luciferase reporter assay, qRT-PCR, and western blotting. Results: The expression level of PITX1 was decreased in GC tissues and cell lines. Elevated PITX1 expression significantly suppressed the cell proliferation of GC cells and tumorigenesis in vitro and in vivo. PITX1 knockdown blocked its inhibition of GC cell proliferation. PITX1 bound to whole genomewide sites, with these targets enriched on genes with functions mainly related to cell growth


and apoptosis. PITX1 bound to PDCD5, an apoptosis-related gene, during tumorigenesis, and cis-regulated PDCD5 expression. Increased PDCD5 expression in GC cells not only induced GC cell apoptosis, but also suppressed GC cell growth in vitro and in vivo. Moreover, PITXI expression was regulated by miR-19a-3p. More importantly, a decreased level of PITX1 protein was correlated with poor GC patient prognosis. Conclusion: Decreased expression of PITX1 predicts shorter overall survival in GC patients. As a transcriptional activator, PITX1 regulates apoptosis-related genes, including PDCD5, during gastric carcinogenesis. These data indicate PDCD5 to be a novel and feasible therapeutic target for GC.

\section{Introduction}

Gastric cancer (GC) remains the third leading cause of cancer-related death worldwide. Although significant progress has been made in its diagnosis as well as in surgical combined adjuvant approaches, the outcomes of GC patients have only modestly improved [1]. In recent decades, considerable research has indicated that several signaling pathways are involved in gastric carcinogenesis and GC progression. The activated HGF/c-MET signaling pathway has been positively associated with an advanced GC tumor stage and poor survival [2-5]. Alteration of the PI3K/Akt/mTOR pathway has been frequently detected in gastric carcinoma [6-8], indicating a potential signaling pathway target for efficacious treatment of GC. In gastric carcinogenesis, STAT3 is activated and functions as a transcription factor that induces a host of target genes, involving those involved in cell proliferation, invasion/ metastasis, and angiogenesis $[9,10]$. A recent notable study provided a more comprehensive molecular evaluation of primary gastric adenocarcinoma tissues [11]. Although these studies revealed many molecular mechanisms of gastric carcinogenesis, we still have a long way to go before completely mastering GC. Therefore, the identification of more molecular mechanisms in GC carcinogenesis and progression may help in the development of novel therapeutic strategies for this cancer.

Gene expression needs to be tightly regulated by transcription factors to achieve a specific pattern of gene activation or repression during development and carcinogenesis. In response to different stimuli, transcription factors regulate tissue-specific and developmental stage-specific gene expression patterns. Paired-like homeodomain transcription factor 1 (PITX1) was first identified as a bicoid-related transcription factor that was involved in proopiomelanocortin gene expression [12]. PITX1 also represses TERT expression in melanoma cell lines [13], interacting functionally with other transcription factors such as SF-1 and basic helix-loop-helix transcription factors [14]. More recently, PITX1 was identified in transcription factor-inducible mouse embryonic stem cell lines and enriched in promoters of binding genes, displaying tissue-specific expression in the placenta, bladder, lung, and stomach [15]. PITX1 controls stomach smooth muscle development through the transcription factor BARX1 [16]. Although homeobox genes were initially identified as being involved in organ development, surprisingly PITX1 was recently reported to also be involved in cancer progression via transcriptional activation of p53 [17] and p120RasGAP [18]. Accumulating evidence indicates that PITX1 functions as a tumor-suppressor gene in various types of human carcinoma. Downregulation of PITX1 has been found in several malignant cancers, including oral squamous cell carcinoma [19], malignant melanoma [20], esophageal cancer [21], lung cancer [22], colorectal cancer [23], and GC [24]. Thus, PITX1 may play a crucial role in the development of carcinogenesis. However, little is known about the tumor-inhibitory mechanism of PITX1 in regulating tumor-related genes and which molecules regulate PITX1 during tumorigenesis.

In this work, we present a novel anti-oncogenic mechanism in which PITX1 activates apoptosis-related genes and suppresses cell proliferation in GC. PDCD5 expression regulated by PITX1 promoted the apoptosis of GC cells. Decreased expression of PITX1 predicted shorter overall survival in GC patients. Additionally, PITX1 expression was modulated by miR-19a-3p in GC.

\section{KARGER}




\section{Materials and Methods}

\section{GC patient samples and GC cell lines}

Paired tumors and adjacent non-tumor gastric tissues from 32 GC patients used for real-time quantitative reverse transcription PCR and 174 primary GC tissues (132 males and 42 females, with a donor age of 37-86 years) designed for tissue microarrays (Shanghai Outdo Biotechnology Co., Ltd., Shanghai, China) were obtained from the First Affiliated Hospital of Nanjing Medical University from 2005 to 2013 after patients provided written informed consent. This study was performed with the approval of the Medical Ethical Committee of the Medical School of Southeast University.

GC cell lines (AGS, BGC-823, MCG-803, and SGC-7901) and a gastric epithelial cell line (GES-1) were purchased from the Institute of Biochemistry and Cell Biology of the Chinese Academy of Sciences (Shanghai, China). All cell lines were maintained in RPMI-1640 medium supplemented with 10\% fetal bovine serum (FBS; Wisent Inc., Montreal, Canada), $100 \mathrm{U} / \mathrm{mL}$ of penicillin, and $100 \mathrm{mg} / \mathrm{mL}$ streptomycin (Invitrogen, Carlsbad, $\mathrm{CA}$ ) in a humidified incubator with $5 \% \mathrm{CO}_{2}$ at $37^{\circ} \mathrm{C}$.

\section{Bioinformatics analysis of RNA sequencing data from The Cancer Genome Atlas}

The Cancer Genome Atlas (TCGA) dataset, a large cancer dataset with high-throughput sequencing data for protein coding genes, was used to investigate the expression of PITX1 at the mRNA level in GC patients. Publicly available Level 3 RNAseq data HTSeq-FPKM, HTSeq-count, and corresponding clinical data of 407 cancer patients were obtained from the TCGA data portal website. The Bioconductor package edge R was used to compute the $\mathrm{p}$ values and fold changes for the RNAseq read count data in the R platform (version 3.2.3). The expression level of PITX1 was extracted from the HTSeq-FPKM data, excluding those patients lacking complete clinical information or with low-quality data, and a box plot was used to show the differential expression of PITX1 between 367 GC tissues and 31 normal gastric tissues.

\section{Immunohistochemical analysis}

Paraffin sections $(4 \mu \mathrm{m})$ from 174 primary GC tissues (detailed information regarding the patients' clinical features is presented in Table 1) were stained with an anti-PITX1 (Abnova, Taipei, Taiwan, China) antibody by incubating the samples overnight at $4^{\circ} \mathrm{C}$. Secondary staining with biotin-conjugated antimouse IgG and tertiary staining with HRP-conjugated streptavidin were performed using an ABC kit (PK6100; Vector, Burlingame, CA). Specific staining was visualized by 3,3 '-diaminobenzidine staining. The sample slides were then counterstained with hematoxylin. Images were captured using a Nikon ECLIPSE TE2000-S microscope system (Nikon, Melville, NY).

Real-time quantitative reverse transcription PCR

Total RNA was isolated using TRIzol reagent (Invitrogen). Firststrand cDNA was synthesized from $1 \mu \mathrm{g}$ of total RNA using Oligo (dT) and AMV reverse transcriptase (Takara, Dalian, China). Real-time PCR was carried out using SYBR Premix Ex Taq (Takara) with the StepOne Plus system (Applied Biosystems, Foster City, CA) according to the manufacturer's protocol. The real-time PCR reactions were performed in triplicate and $\beta$-actin was used as the internal control. The relative expression level of target RNAs was evaluated by the comparative CT $\left(2^{-}\right.$ $\triangle \Delta C T)$ method. The primer sequences of each gene are shown in Table 2.

\section{Plasmid construction}

PITX1 cDNA was isolated by reverse transcription PCR and then cloned into the HindIII/EcoRI sites of pcDNA3.1. The primer sequences are shown in Table 2. pReceiver-M13-PDCD5 and control plasmid pReceiver-M13 were purchased from GeneCopoeia Corporation (Guangzhou, China).

Table 1. Clinical features of the patients recruited in the present study

\begin{tabular}{lc}
\hline Parameters & samples \\
\hline Gender & 132 \\
male & 42 \\
female & \\
Age & 64 \\
$\leq 60$ & 110 \\
$>60$ & \\
Pathological grade & 3 \\
Well & 6 \\
Well-morderate & 74 \\
Morderate & 9 \\
Morderate-poor & 78 \\
poor & 4 \\
No & \\
Clinical stage & 5 \\
0 & 14 \\
I & 7 \\
I - II & 66 \\
II & 16 \\
II -III & 52 \\
III & 14 \\
IV & \\
\hline
\end{tabular}


Qiao et al.: PITX1 Modulated by MiR-19a-3p Promotes Gastric Cell Malignancy by Affecting Transcriptionally Activated PDCD5

PITX1 ShRNA and siRNA and PDCD5 SiRNA

PITX1 shRNA was purchased from Origene Company (Beijing, China). PITX1 and PDCD5 siRNA were synthesized by GenePharma (Shanghai, China). The sequences were as follows: PITX1 siRNA 1, 5'-ATCGCCGTGT GGACCAACCTCACCGAGCC-3'; PITX1 siRNA 2,5'-CACTTCACAAGCCAGCAGTT GCAAGAGCT-3'; PDCD5 SiRNA 1, sense, 5'-GCAGAAAUGAGAAACAGUATT-3; antisense, 5'-UACUGUUUCUCAUUUCUGCTT-3'; siRNA 2, sense, 5'-GGCCAGGUUAAGUAACUUATT-3'; antisense, 5'-UAAGUUACUUAACCUGGCCTT-3'; siRNA 3, sense, 5'-GGCAAGAUAUGGACAACUATT-3'; antisense, 5'-UAGUUGUCCAUAUCUUGCCTT-3'.

\section{Cell transfection}

AGS and BGC-823 cells were transiently transfected with $2 \mu \mathrm{g}$ of the pcDNA3.1-PITX1 construct or the control pcDNA3.1 using the X-tremeGENE HP DNA transfection reagent (Roche, Mannheim, Germany) according to the manufacturer's protocol. Stably expressing PITX1 shRNA cells (MCG-803 \#1 and MCG-803 \#10) and the control cells (MCG-803 NC) were established and cultured in medium with puromycin. Cells were transfected with $50 \mathrm{nmol} / \mathrm{L}$ PDCD5 (GenePharma) or negative control siRNA using the X-tremeGENE siRNA Transfection Reagent (Roche) according to the manufacturer's protocol. After $48 \mathrm{~h}$, cells were harvested for analysis.

miR-19a-3p mimics and negative control molecules (scramble control mimic) were synthesized and purified by GenePharma. They were transfected into cells at a final concentration of $50 \mathrm{nM}$ using Lipofectamine-2000 transfection reagent (Invitrogen) according to the manufacturer's protocol.

\section{Measurement of cell proliferation}

AGS or BGC-823 cells (1000 per well) were plated and transiently transfected with pPITX1 construct, and the MCG-803 cells were stably transfected with PITX1 shRNA in 96-well plates. The cell proliferation ability was measured with a Cell Counting Kit-8 (CCK-8) for 5 days (Dojindo Laboratories, Kumamoto, Japan). The optical density was measured at a wavelength of $450 \mathrm{~nm}$ with a microplate reader (Bio-Rad, Hercules, CA). Triplicate independent experiments were performed.

Cells $\left(3.5 \times 10^{3}\right)$ were plated in 96-well plates in three replicates for $24 \mathrm{~h}$. These cells were then incubated with 5-fluorouracil (Sigma, Ronkonkoma, NY) (AGS in $25 \mu \mathrm{M}$, BGC-823 in $25 \mu \mathrm{M}$, MCG-803 in $12.5 \mu \mathrm{M}$, SGC7901 in $6.25 \mu \mathrm{M}$ ) or cisplatin (Sigma) (AGS in $20 \mu \mathrm{M}, \mathrm{BGC}-823$ in $5 \mu \mathrm{M}$, MCG-803 in $2.5 \mu \mathrm{M}$, SGC-7901 in $2.5 \mu \mathrm{M}$ ) for $24 \mathrm{~h}$. After treatment for the indicated times, CCK- 8 was added to the culture for $3 \mathrm{~h}$ prior to the measurement of absorbance at $450 \mathrm{~nm}$ with triplicate independent experiments.

\section{Western blot analysis}

Western blots were performed using anti-PITX1 (Abnova), anti-caspase-3 (Cell Signaling Technology, Boston, MA), anticaspase-8 (Cell Signaling Technology), anticaspase-9 (Cell Signaling Technology), antiPDCD5 (Abcam, Cambridge, UK) and anti- $\beta$ actin (Sigma) antibodies and detected using Super Signal chemiluminescence substrate (Pierce, Rockford, IL).

Chromatin immunoprecipitation and sequencing

Chromatin immunoprecipitation (ChIP) experiments were performed using an EZ ChIP $^{\text {тм }}$ Chromatin Immunoprecipitation Kit for cell line samples (Millipore, Billerica, MA)

Table 2. Primers used in this study

\begin{tabular}{|c|c|c|}
\hline Genes & sequences & $\begin{array}{l}\text { Product } \\
\text { size (bp) }\end{array}$ \\
\hline \multirow[t]{2}{*}{ PITX1 } & F: 5'-TCCACCAAGAGCTTCACCTT-3' & 166 \\
\hline & R: 5'-CGGTGAGGTTGTTGATGTTG - $3^{\prime}$ & \\
\hline \multirow[t]{2}{*}{$\beta$-actin } & F: 5'- AAAGACCTGTACGCCAACAC-3' & 220 \\
\hline & R: 5'- GTCATACTCCTGCTTGCTGAT-3' & \\
\hline \multirow[t]{2}{*}{ PITX1-pcDNA3.1 } & F: 5'-CCCCAAGCTTATGGACGCCTTCAAGGGGG-3' & 970 \\
\hline & R: 5'-GGTG GAATTCGGCGGTCAGCTGTTGTACTGG -3' & \\
\hline \multirow[t]{2}{*}{ PDCD5 } & F:5'-GGTATTGAGGGTCCGCTGTG-3' & 205 \\
\hline & R: 5'-AACGGGCCTCGGTATTAGG-3' & \\
\hline \multirow[t]{2}{*}{ TERT } & F: $5^{\prime}$ - TTTCCAAACCGCCCCTTT- $3^{\prime}$ & 151 \\
\hline & R: 5'-CTGTCACGCTCGCTGGAG-3' & \\
\hline \multirow[t]{2}{*}{ GFI1 } & F:5'-CAACGACGGCGGGTTC-3' & 169 \\
\hline & R:5'-GGTGGAGACGTGGGTCAGTA-3' & \\
\hline GAPDH & Provided by kit & 60 \\
\hline \multicolumn{3}{|l|}{ PDCD5 promoter: } \\
\hline \multirow[t]{2}{*}{$-855 \sim 947$} & F: 5'-TAATACGCGTCCAAGTCAAAGGCAGAAGG-3' & 1823 \\
\hline & R: 5'-GGCGAGATCTAACGGTTCTGTTGTTTCCTAT-3' & \\
\hline \multirow[t]{2}{*}{ TP73 transcript } & F: 5'-GAAGATGGCCCAGTCCACCGC-3' & 80 \\
\hline & R: 5'-GGTCTGGTTCCAGAGAGCTCCA-3' & \\
\hline \multirow[t]{2}{*}{ PDCD5 transcript } & F:5'-TCCTAGACTTGTTCCGTTAAG-3' & 199 \\
\hline & R: 5'-ACAGATGGCAAGATATGGACA-3' & \\
\hline \multirow{2}{*}{ PITX1-3'UTR } & F: 5'-TATTA $\underline{G C T A G C C C C A G G A T C G G G C A C T C A-3 '}$ & 443 \\
\hline & R: 5'-ATTAGTCGACTGCTTAGCACGCTCGGACTA-3' & 443 \\
\hline \multirow{2}{*}{ PITX1-3' UTR mut } & F: 5'-CCCTGCGCCCACGCCATCTGCCCGCTCTCCGG-3' & \multirow{2}{*}{7781} \\
\hline & R: 5'-CGGGCCGGAGAGCGGGCAGATGGCGTGGGCGCAGGGCCC-3' & \\
\hline
\end{tabular}


ing Transcriptionally Activated PDCD5

according to the manufacturer's instructions. Briefly, the crosslinked chromatin DNA was sonicated into 200 to $1000 \mathrm{bp}$ fragments and then fixed with $1 \%$ formaldehyde. Immunoprecipitation was performed using an anti-PITX1 antibody or normal mouse IgG as the negative control. All standard protocols for sequence preparation, sequencing, and quality control were provided by Illumina (San Diego, CA). In short, DNA recovered from a conventional ChIP procedure was quantified using a QuantiFluor fluorometer (Promega, Madison, WI). DNA integrity was verified using the Agilent Bioanalyzer 2100 (Agilent, Palo Alto, CA). The DNA was then processed, including end-repair, adaptor ligation, and size selection, using an Illumina sample prep kit following the manufacturer's instructions (Illumina). Final DNA libraries were validated and sequenced at 75 bp per sequence read using an Illumina GAIIx sequencer at a depth of approximately 30 million sequences per sample.

\section{ChIP-seq analysis}

ChIP DNA end-repair, adaptor ligation, and amplification were performed according to the manufacturer's protocol. Fragments were isolated from agarose gels and used for sequencing with a Solexa/ Illumina 2G genetic analyzer (CD Genomics, Shirley). Sequencing tags were aligned to the reference genome using SOAP 2.21 (Beijing Genomics Institute [BGI], Shenzhen, China) and Bowtie. We considered those tags that aligned uniquely with less than two mismatches. For enriched-region (peak) identification (peak calling), we used the Model-based Analysis of ChIP-seq (MACS) algorithm with MACS version 1.4.0 software (BGI). A simple yet effective technique for the analysis of eukaryotes, MACS was designed to identify transcription factor binding sites and histone modification-enriched regions in ChIP-seq data sets, with or without control samples. Sequence reads mapping to multiple sites in the human genome were removed. The MACS program was used to determine enriched PITX1 peaks using IgG-ChIP as control. Peaks were displayed through the UCSC Genome Browser (http://genome.ucsc.edu/). The annotation regions of these peaks covered from $2 \mathrm{~kb}$ upstream of the transcription start site to $2 \mathrm{~kb}$ downstream of the transcription termination site. AmiGO is accessible online at the Gene Ontology (GO) website (http://www.geneontology. $\mathrm{org} /$ ) for users to obtain the data provided by the GO Consortium. MEME 4.7.0 was used for motif discovery in this study.

\section{Luciferase reporter assay}

A fragment of the PDCD5 promoter region was used here (-855 bp to $947 \mathrm{bp})$. All fragments were synthesized by PCR using genomic DNA from the GES-1 gastric epithelial cell line. The PCR primers used for the PDCD5 promoter region are listed in Table 2. The PCR products were inserted upstream of the luciferase gene in the pGL3-basic plasmid (Promega), and the correct sequences of all clones were verified by DNA sequencing. Promoter activity was measured using the Luciferase Reporter Assay System (Promega). AGS cells were plated in a 12-well plate and transfected with TP73 or PDCD5 promoter fragments and the pGL3basic empty vector using Lipofectamine $2000^{\mathrm{TM}}$ (Invitrogen). Cells were harvested at $48 \mathrm{~h}$ post-transfection and the luciferase reporter assay was performed using the cell lysate. The experiments were performed three times in triplicates and the results are reported as the mean \pm standard deviation (SD).

The amplified PITX1 wide-type or mutant fragments were cloned into the NheI and AccI restriction sites of the pmiRGLO Luciferase plasmid (Promega) using the In-Fusion Dry-Down PCR Cloning Kit (TaKaRa Bio Inc., Shiga, Japan). The primers are shown in Table 2. AGS cells were seeded into 96-well plates with transfection mixture. Luciferase activity was recorded using the Dual-Glo Luciferase Assay System (Promega) by normalization to Renilla luciferase activity according to the manufacturer's instructions.

\section{Cell synchronization and DNA content analysis by flow cytometry}

Cells were incubated in complete RPMI-1640 medium containing 10\% FBS for G0/G1 phase synchronization. When the cells reached $40 \%$ confluency, they were treated with mimosine $(400 \mu \mathrm{M})$ for 12 h. After treatment, cells were released in complete medium for different time courses and collected for DNA content analysis. Cell cycle distribution was examined by flow cytometry using a FACScan flow cytometer (Becton Dickinson \& Co., San Jose, CA). The relative number of cells in each phase of the cell cycle was analyzed using the Modfit program (Verity Software House, Inc., Topsham, ME).

\section{Cell apoptosis analysis by flow cytometry}

Early apoptotic cells were detected using the Annexin V-PI apoptosis detection kit (Biouniquer, Hangzhou, China). PDCD5-induced cell apoptosis was treated with $0.5 \mu \mathrm{M}$ staurosporine for $12 \mathrm{~h}$ before detection in the GC cell lines AGS and BGC-823. 


\section{Tumor xenograft mouse model}

Approximately $1 \times 10^{7}$ cells were subcutaneously injected into the right or left dorsal flanks of 4-weekold nude mice $(\mathrm{n}=5)$. Tumor formation was monitored over a 4-week period. The tumor volume was measured weekly and calculated by the following formula: $\mathrm{V}=0.5 \times \mathrm{L} \times \mathrm{W}^{2}$. All experiments were conducted in accordance with the institutional standard guidelines of Southeast University for animal experiments.

\section{Electrophoretic mobility shift assay}

5 '-Biotinylated oligonucleotides of $25 \mathrm{bp}$ in length were obtained from BGI. Oligonucleotide sequences for $P D C D 5$ probes are listed in Fig. 6. For annealing, concentrated complementary oligonucleotides were mixed at a $1: 1$ molar ratio and incubated at $95^{\circ} \mathrm{C}$ for $5 \mathrm{~min}$; the temperature was then gradually reduced over several hours until the oligonucleotides reached room temperature. Annealed oligonucleotides were diluted to a final concentration of $100 \mathrm{fmol}$. Nuclear proteins were extracted from AGS-pcDNA3.1 and AGSpPITX1 cells using NE-PERTM Nuclear and Cytoplasmic Extraction Reagents (Pierce) according to the manufacturer's instructions. The LightShift Chemiluminescent electrophoretic mobility shift assay (EMSA) kit (Pierce/Thermo Fisher Scientific) was used according to the manufacturer's instructions. Briefly, binding reactions were performed as follows: nuclear extracts ( $8 \mu \mathrm{g}$ protein) and the $1 \times$ binding buffer with $2.5 \%$ glycerol, $5 \mathrm{mM} \mathrm{MgCl}, 50 \mathrm{ng} / \mu \mathrm{L}$ poly $(\mathrm{dI}-\mathrm{dC}), 0.05 \% \mathrm{NP}-40$, and $60 \mathrm{fmol}$ biotin-labeled probes were incubated on ice for $30 \mathrm{~min}$ in a volume of $20 \mu \mathrm{L}$. For competition studies, nuclear extracts were incubated with unlabeled oligonucleotide for $30 \mathrm{~min}$ before the addition of labeled oligonucleotide. Complexes were separated by electrophoresis on native $6 \%$ PAGE in $0.5 \times$ TBE buffer at $110 \mathrm{~V}$. Gels were transferred to Biodyne B pre-cut modified nylon membranes (Pierce/Thermo Fisher Scientific) using a Trans-Blot SD semi-dry transfer cell (Bio-Rad Laboratories). Membranes were crosslinked (UVC-508 UV Cross-linker, Ultra LUM) and the signal was detected with a chemiluminescent detection system (Pierce/Thermo Fisher Scientific) according to the manufacturer's instructions.

\section{Statistical analysis}

The mRNA expression level of PITX1 in the GC and matched non-tumor tissue was compared using a paired Student's t-test. An independent Student's t-test was used to compare the results (expressed as the mean \pm SD) between any two pre-selected groups. One-way analysis of variance and Dunnett's test were applied to compare data between three or more groups. $P<0.05$ was considered statistically significant.

\section{Results}

Decreased expression of PITX1 protein and poor prognosis of GC patients

PITX1 protein was originally described as a member of the homeobox transcription factor family involved in the transcriptional regulation of proopiomelanocortin gene in the adult pituitary gland [12]. It was subsequently identified as a possible tumor-suppressor gene in various types of human carcinoma. In the present study, we found that PITX1 expression was downregulated at the transcriptional level in 44\% (14/32) of GC patients of the Jiangsu province of China (Fig. 1A). Additionally, 4 GC cell lines showed a different expression level of PITX1 from the GES-1 gastric epithelial cell line (Fig. 1B). In order to correlate the PITX1 level with GC, we combined the TCGA dataset, which consists of high-throughput sequencing data for protein coding gene expression, into the next analysis. The data indicated that PITX1 had significantly decreased expression in the $367 \mathrm{GC}$ tissues compared with the 31 normal gastric tissues $(P=1.23 \mathrm{E}-06)$ (Fig. 1C). Next, the PITX1 protein level was detected in GC tissues by immunohistochemical analysis in a tissue microarray containing $174 \mathrm{GC}$ samples. A tissue microarray assay (TMA) revealed that PITX1 protein was mainly expressed in the cell nucleus (Fig. 1D).

To demonstrate the clinical significance of the decreased levels of PITX1 in GC patients, the Kaplan-Meier method was used to compare prognoses among patients with high and low expression levels of PITX1. The mean level of PITX1 protein in the TMA was used as the cutoff to divide patients with cancer into high and low PITX1 expression level groups. The results indicated that GC patients with lower levels of PITX1 had a worse prognosis than those with higher levels of PITX1 $(P=0.027$; Fig. 1E). 
Fig. 1. The correlation between PITX1 expression level and patients' prognosis. A. PITX1 expression level was detected by qPCR in gastric cancer tissues. B. PITX1 expression level was evaluated in 4 gastric cancer cells and an immortalized normal gastric mucosa cell line GES-1. C. Analysis of PITX1 expression in 367 gastric cancer tissues and 31 normal tissues based on the data from Cancer Genome Atlas (TCGA). D. Immunohistochemical staining of PITX1 protein in representative gastric cancer samples $(n=174)$. Positive immunohistochemical staining of PITX1 protein was showed in cell nucleus. E. The Kaplan-Meier survival curve of gastric cancer patients stratified into two group by low and high expression level of PITX1.

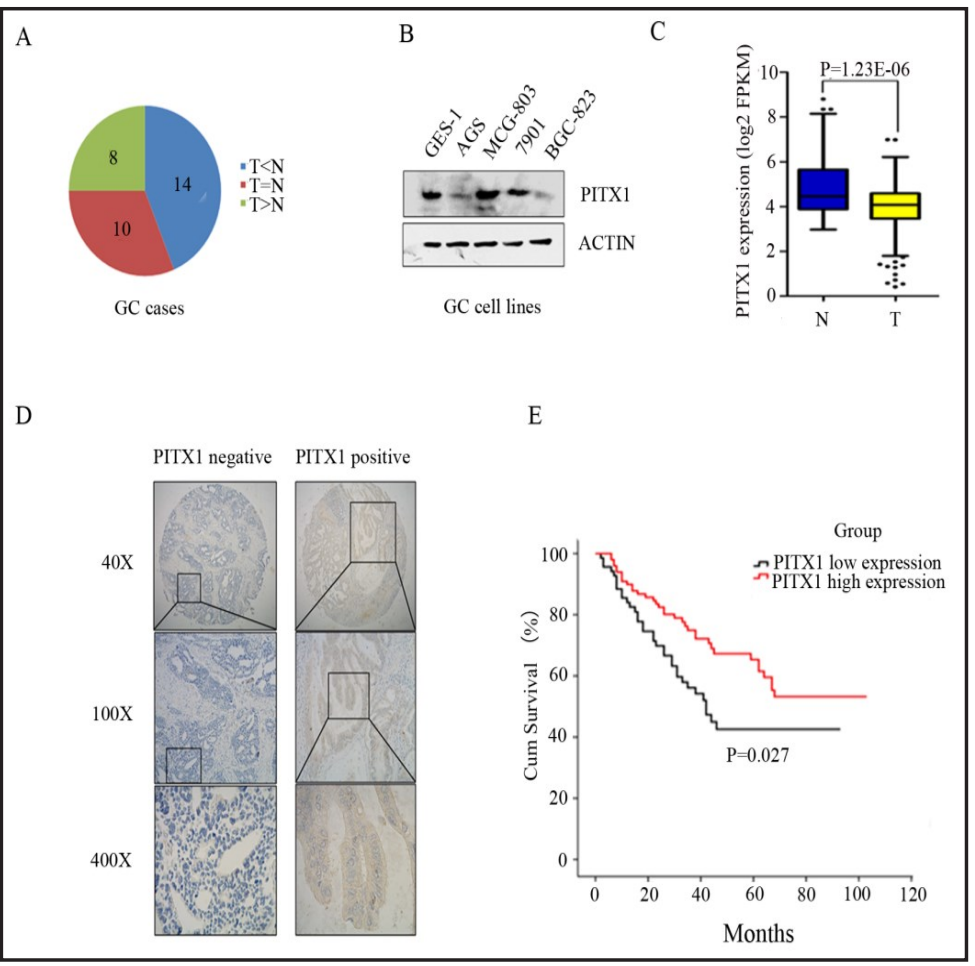

Patients with high PITX1 expression level were more likely to survive longer compared with patients with low PITX1 expression level $\left({ }^{*} \mathrm{P}<0.05\right)$. N: non-tumor, T: tumor.

Fig. 2. PITX1 suppressed cell proliferation of GC cells in vitro. A. Cell proliferation was measured by Cell Counting Kit-8 (CCK-8) assay. Inhibition of cell growth was detected in AGS-pPITX1 and BGC-pPITX1 cells compared with AGS-pcDNA3.1 and BGC-pcDNA3.1 cells. B. Promotion of cell growth was detected in two PITX1 shRNA transfectants MCG-PITX1 shRNA \#1 and MCG-PITX1 shRNA \#10 compared with the control cells MCG-803-NC $\left({ }^{*} \mathrm{P}<0.05,{ }^{* *} \mathrm{P}<0.01\right.$, independent Student's t-test). C. Fluorescent activated cell sorting (FACS) was used to analyze the cell cycle of AGS-pPITX1, BGC-pPITX1 and MCG-PITX1shRNA cells. M1: G1 phase, M2: S phase, M3: G2 phase. The bar chart represents the relative percentages of cells in each phase. The values indicate the mean \pm SD for three separate experiments $\left({ }^{*} \mathrm{P}<0.05,{ }^{* *} \mathrm{P}<0.01\right.$, Student $\mathrm{t}$-test $)$.

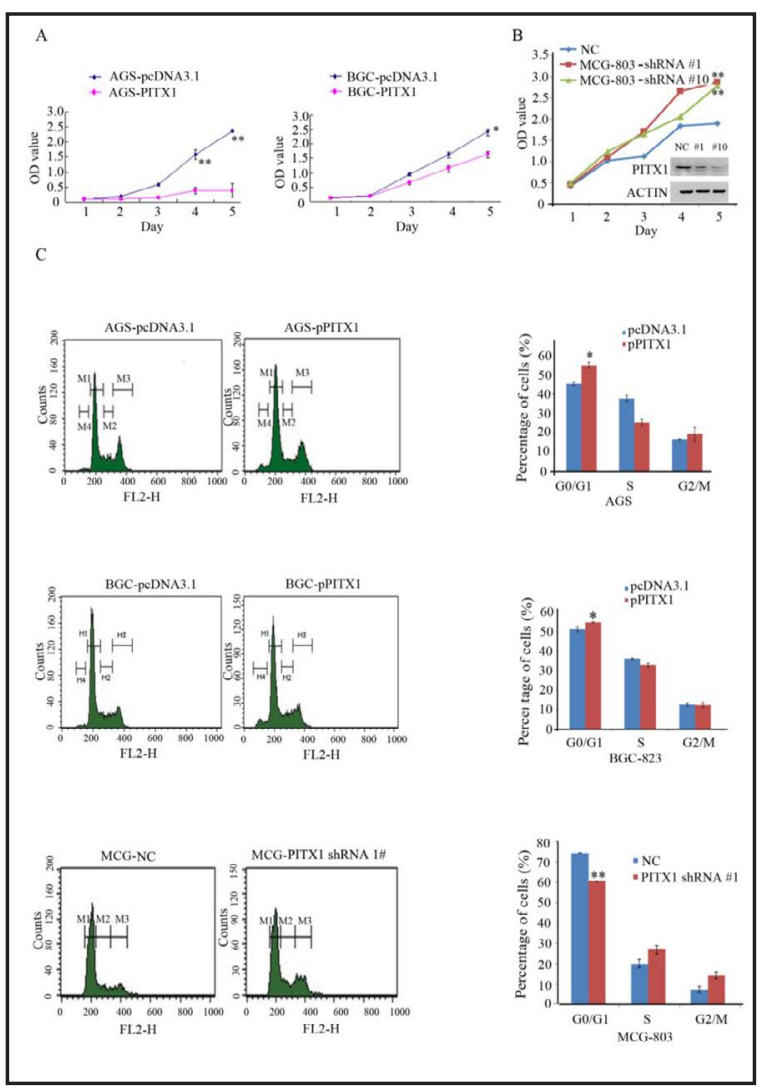


A

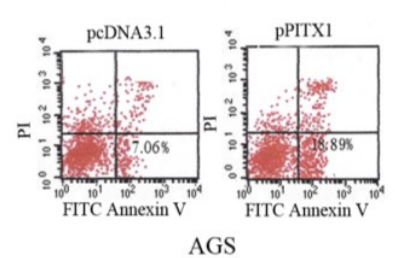

AGS
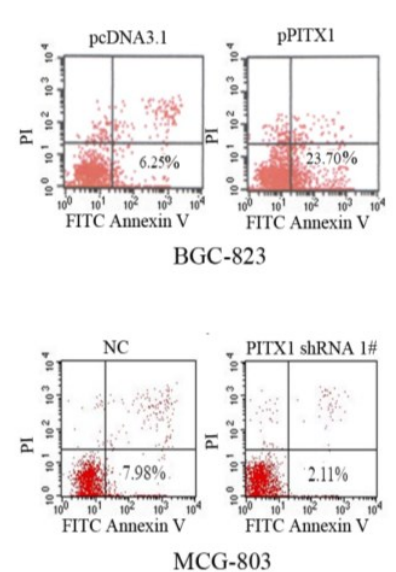

B

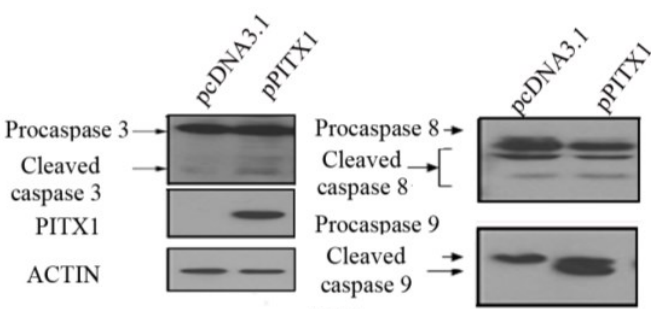

AGS
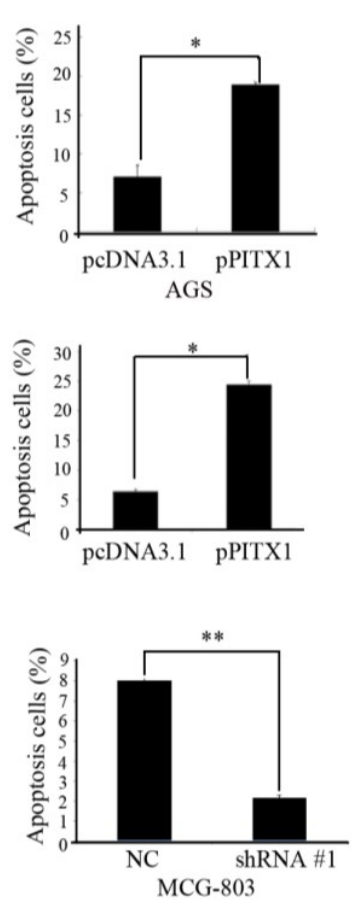

$\mathrm{C}$

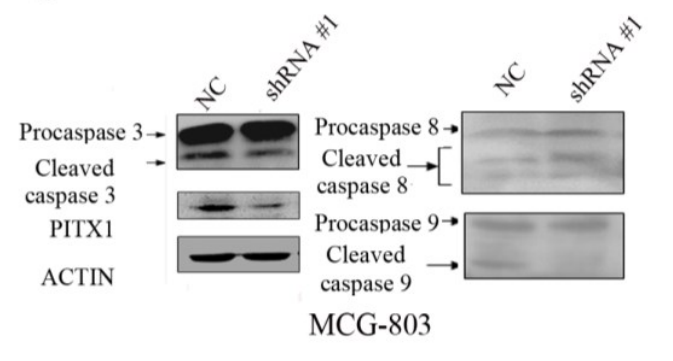

Fig. 3. Enforced expression of PITX1 induced cell apoptosis in GC cells. A. Flow cytometry analysis of cell apoptosis in AGS and BGC-823 cells transfected with pcDNA3.1 and pPITX1 constructs and MCG-803 cells with NC and PITX1 shRNA constructs. The apoptosis rate was calculated and depicted in a bar chart. The values indicate the mean \pm SD for three separate experiments (Student $t$-test, ${ }^{*} \mathrm{P}<0.05,{ }^{* *} \mathrm{P}<0.01$ ). B. Western blot analysis for cleaved caspase-3, caspase-8 and caspase-9 in AGS cells transiently transfected with pPITX1 and pcDNA3.1 constructs, respectively. C. Western blot analysis for cleaved caspase-3, caspase-8 and caspase-9 in MCG-803 cells stably transfected with NC and PITX1 shRNA constructs. The data are representative of three independent experiments $\left({ }^{*} \mathrm{P}<0.05,{ }^{* *} \mathrm{P}<0.01\right.$, Student $\mathrm{t}$-test $)$.

PITX1 suppresses cell growth by arresting the cell cycle at the G1/S phase and inducing cell apoptosis in GC cell lines

The function of PITX1 in GC remains to be elucidated. We first tested if PITX1 affected cell growth. PITX1 significantly inhibited cell proliferation when it was transiently overexpressed in AGS and BGC-823 cells (Fig. 2A). In addition, cell proliferation ability was improved in MCG-803-shRNA \#1 and \#10 cells with downregulated PITX1 (Fig. 2B). In order to determine whether PITX1 suppressed the cell growth of GC cells, we studied the cell cycle using flow cytometry. As expected, we found that ectopic expression of PITX1 significantly increased the percentage of AGS and BGC-823 cells in the G1 phase. In contrast, knockdown of PITX1 in MCG-803 cells significantly reduced the percentage of cells in the G1 phase and 
increased cell percentages in the S phase $\left({ }^{*} P<0.05\right.$, ${ }^{* *} P<0.01$; Fig. $\left.2 \mathrm{C}\right)$, suggesting that PITX1 may delay cell cycle progression and arrest GC cells at the G1/S transition.

We further checked whether PITX1 contributes to cell apoptosis in GC cells. We stained the cells with Annexin V and measured the apoptotic cells by flow cytometry. Overexpression of PITX1 resulted in a clear increase in apoptotic AGS and BGC-823 cells. The apoptosis rate was $7.06 \%$ in the AGS-pcDNA3.1 cells but $18.89 \%$ in the AGS-pPITX1 cells. In another group of cells, the apoptosis rates were $6.25 \%$ and $23.7 \%$ in BGC-pcDNA3.1 and BGC-pPITX1 cells, respectively. Decreased expression of PITX1 with MCG-PITX1 shRNA \#1 inhibited cell apoptosis compared with MCG-NC cells (2.11\% vs. $7.98 \%)\left({ }^{*} P<0.05,{ }^{* *} P<\right.$ 0.01; Fig. 3A). To further examine the mechanism of PITX1 involved in its promotion of cell apoptosis, we measured the protein expression of several apoptotic markers. As shown in Fig. 3B, overexpression of PITX1 significantly elevated the expression of cleaved caspase-3 and cleaved caspase-9 in AGS-pPITX1 cells compared with AGS-pcDNA3.1 cells. In contrast, knockdown of PITX1 with MCG-PITX1 shRNA \#1 reduced the expression of cleaved caspase-3 and cleaved caspase-9 compared with MCG-NC cells (Fig. 3C). Alteration of cleaved caspase-8 was not clear in any of the tested cells. These results further indicated that PITX1 contributes to induce cell apoptosis in GC.

\section{Decreased expression of PITX1 promotes tumor cell growth in vivo}

To investigate the tumor-suppressive effects of PITX1 in vivo, 5 nude mice (one mouse died during the assay) were subcutaneously inoculated with MCG-PITX1 shRNA \#1 or control MCG-NC cells. Compared with the negative control group, 3 mice with PITX1 knockdown showed a significantly higher tumor growth in terms of volume and weight (Fig. $4 \mathrm{~A}-\mathrm{C}$ ). Meanwhile, we determined the PITX1 expression level and found that the size of the neoplasm was consistent with the PITX1 expression level (Fig. 4D and E). These data further demonstrated the paramount role of PITX1 in inhibiting GC tumor cell growth both in vitro and in vivo.

Fig. 4. Elevated expression of PITX1 suppressed tumor growth in vivo. A. Images of tumors formed in the nude mice injected with the indicated cells. The MCG-803 negative control (NC) or MCG803 PITX1 shRNA \#1 cells were injected into the left and right dorsal flanks $(n=4)$, respectively (one mouse died). $B$ and C. PITX1 knockeddown significantly promoted tumor growth in tumor sizes and weights in nude mice. Tumor volumes were calculated after injection every week. Bars indicate SD. A sterisk indicates a significant change $\left({ }^{*} \mathrm{P}<0.05,{ }^{* *} \mathrm{P}<0.01\right)$. Data are the mean \pm SD. D and E. Relative expression level of PITX1 mRNA and protein in nude mice.

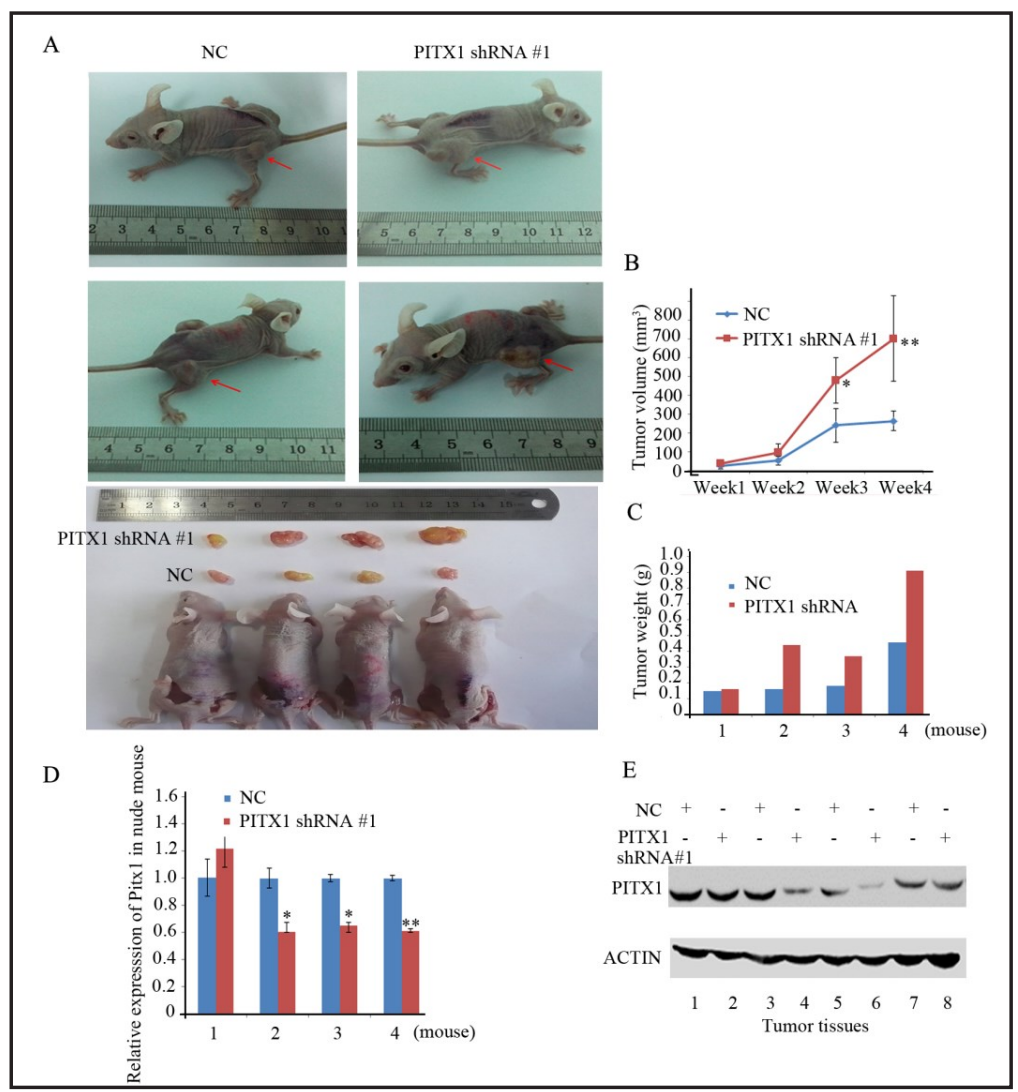


A

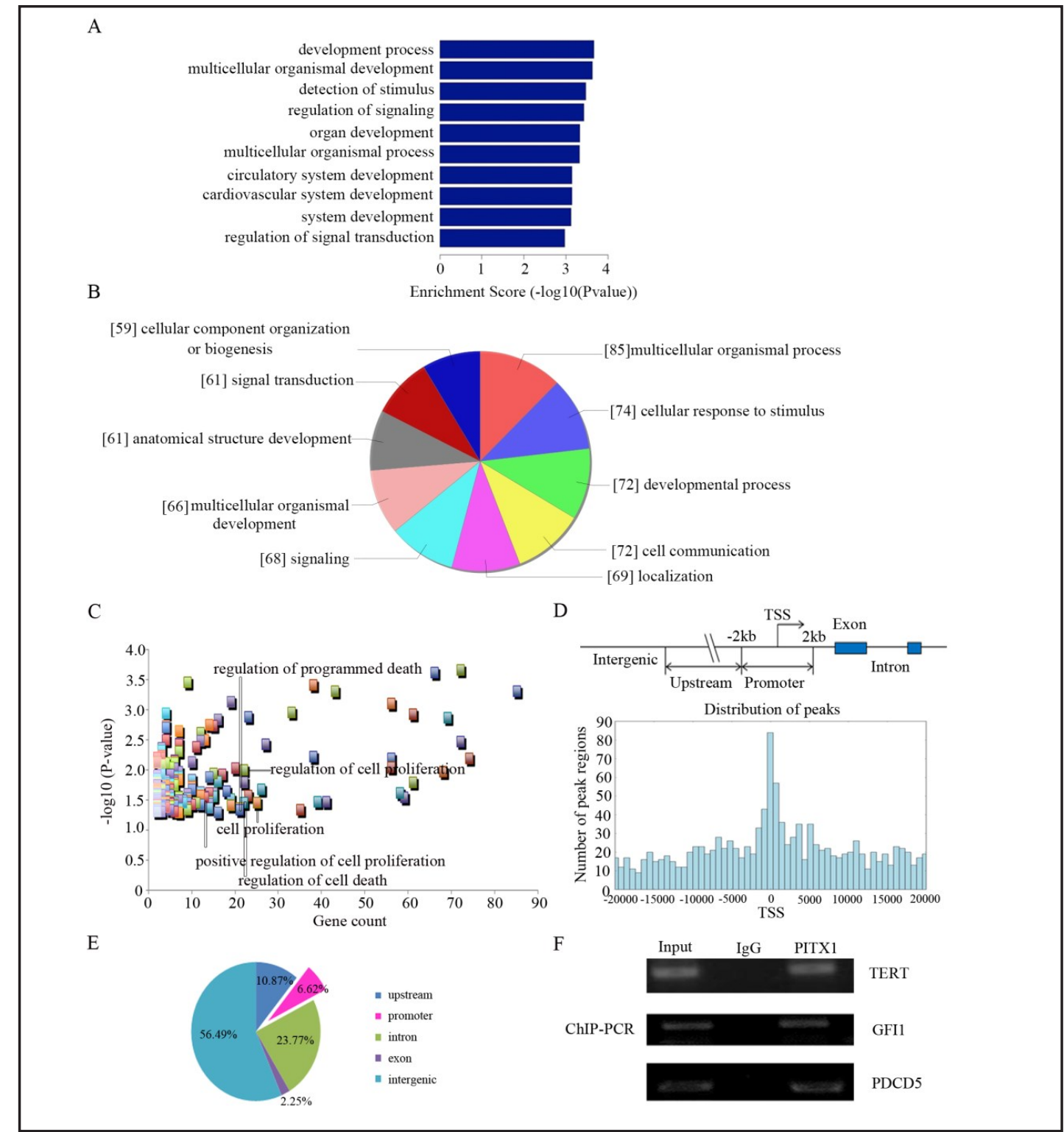

Fig. 5. PITX1 binding sites were detected and evaluated by ChIP-seq. A and B. Function annotation for PITX1 targeted genes of biological process in cancer.The vertical axis showed the annotated functions of the target genes. The horizontal axes showed - $\log 10$ transformed P-value and the gene number of each cluster respectively. Only the most significantly enriched clusters were included. C. The scatter plots demonstrated all cluster features about P-value and gene count, and the plots on the top right corner represent high significance and more genes. Cell proliferation and apoptosis were labeled with high significance and more genes.D. The ideograph and histograms of PITX1 binding sites around annotated TSS (transcription start sites) (+ or $-20 \mathrm{~kb}$ ). Number of peak regions was shown in Y-axis. Relative distance to TSS was indicated in X-axis, negative and positive value illustrated localization 5' or 3' to TSS respectively. E. Frequencies of PITX1 binding at genes' upstream, promoter, intron, exon and intergenic. F. PITX1 binding at TERT, GFI1 and PDCD5 promoters was validated by PCR. Input and IgG were positive and negative controls respectively.

\section{Genomic profile distribution of genes binding to PITX1 in GC cells}

PITX1 protein acts as a transcriptional regulator involved in the basal and hormoneregulated activity of prolactin [25]. To define the genomic targets of PITX1 and investigate how PITX1 suppresses tumor growth, we performed PITX1 ChIP, which we then sequenced, to 
map the PITX1-binding regions of the human genome and identify the direct transcriptional targets of PITX1. More than 4000 binding sites were detected and categorized based on their locations relative to the genes in the human genome using the annotation functions of CisGenome. The mapping was done with the gene annotations from the UCSC genome annotation database (02/2009) for the human genome (GRCh37/hg19). The function annotation analysis revealed that these genes were significantly correlated with cell proliferation and apoptosis (Fig. 5A-C). We tabulated the frequencies of PITX1 binding sites to transcription start sites (TSSs) for every $1 \mathrm{~kb}$. A histogram of PITX1 binding sites residing within the downstream $20 \mathrm{~kb}$ or upstream $20 \mathrm{~kb}$ genomic regions relative to the annotated TSSs is shown in Fig. 5D. Most of the PITX1 binding regions were identified around the TSS sites (Fig. 5D). Approximately four-fifths of these were located in intron or intergenic regions, suggesting that PITX1 may regulate gene expression by binding to distal regulatory elements. Consistent with the importance of PITX1 in regulating gene expression by binding to core promoters of its targets, about $6.62 \%$ of the regions can be mapped to the gene promoters within $2 \mathrm{~kb}$ of the TSS (Fig. 5E).

Using GOminer analysis, we found that the PITX1 binding genes mainly participated in cell growth and cell apoptosis, which was consistent with the observation that overexpression of PITX1 inhibited cell proliferation in AGS and BGC-823 cells and induced cell apoptosis in MCG-823 cells (Fig. 2 and Fig. 3). Other interesting enriched GO terms included cell differentiation (GO: 0030154), signal transduction (GO: 0007165), regulation of development progress (GO: 0050793), and tissue development (GO: 0009888) (Fig. 5B). To confirm the ChIP-seq results, three genes were validated by ChIP-PCR: TERT, which is regulated by PITX1 [13, 26]; GFI1, which plays a role in G1 phase arrest in the cell cycle [27]; and PDCD5, which induces GC cell apoptosis $[28,29]$. These results confirmed enrichment of the genes in the ChIP DNA pulled down by the PITX1 antibody compared with the mouse negative control IgG (Fig. 5F). PDCD5, a cell apoptosis-related gene, was thus a candidate gene for further research.

\section{PITX1 binds to the PDCD5 promoter and regulates its expression}

The consensus sequence of the AT-rich motif in PITX1 is shown in Fig. 6A. We conducted a luciferase reporter assay to analyze whether PITX1 regulates PDCD5 transcription. We cloned the promoter of PDCD5 (-855 to $947 \mathrm{bp)} \mathrm{into} \mathrm{a} \mathrm{luciferase} \mathrm{reporter} \mathrm{construct.} \mathrm{The}$ assay showed that the transcription activity of the motif was significantly higher in AGS cells transfected with pPITX1 than in cells transfected with pcDNA3.1 plasmids without the motif region $(* P<0.05$; Fig. 6B). Moreover, an EMSA was applied to certify the physical interaction of PITX1 with PDCD5. As shown in Fig. 6C, we found that the motif of PDCD5 specifically interacted with PITX1 protein. The data indicated that PITX1 directly bound to the PDCD5 promoter in vitro. Furthermore, we detected PDCD5 expression in AGS-pPITX1, BGC-pPITX1, and MCG-PITX1 shRNA cells. The results revealed that elevated PITX1 expression increased the expression level of PDCD5 in AGS-pPITX1 and BGC-pPITX1 cells, whereas decreased PITX1 expression reduced the expression level of PDCD5 in MCG PITX1 shRNA cells (Fig. 6D and E). Similarly, it was observed that there was a positive correlation between the PDCD5 expression level and PITX1 protein level in mice injected with MCG-PITX1 shRNA cells (Fig. $6 \mathrm{~F}$ ). These results implied that PITX1 directly regulated PDCD5 gene transcription by binding to its promoter region not only in vitro, but also in vivo.

\section{PDCD5 promotes cell apoptosis in GC cell lines}

To further evaluate whether PITX1 exerted its function on cell apoptosis by regulating PDCD5, we increased the expression of PDCD5 in AGS and BGC-823 cells and knocked down PDCD5 expression in MCG-803 cells (Fig. 7A and C). We measured cell apoptosis in the cells by flow cytometry and Annexin $\mathrm{V}$ staining. The results demonstrated that overexpression of PDCD5 induced cell apoptosis and that knockdown of PDCD5 reduced programmed cell death (Fig. 7B and D). Collectively, these data indicated that PITX1 may target the PDCD5 promoter to induce cell apoptosis in GC.

\section{KARGER}


Fig. 6. PITX1 bound to PDCD5 promoter in vitro and in vivo. A. The consensus sequence of PITX1 binding identified and PDCD5 promoter was an example of PITX1 binding sites. B. Effects of PITX1 on the transcriptional activity of PDCD5 in AGS cells detected by luciferase reporter assay. Data represent the ratios of firefly luciferase activity derived from pPITX1 or pGL3 Basic over renilla luciferase activity derived from pRL-TK relative to the control (pcDNA3.1 and pGL3 Basic). Results are expressed as mean mean \pm SD of at least three experiments. C. Nuclear proteins binding activity of PDCD5 in EMSA. Biotinylated probes were incubated with nuclear extracts from AGS cells. EBNA protein and corresponding combining DNA was a positive control. D, E. Relative expression of PDCD5 in pPITX1 or PITX1 shRNA in AGS, BGC-823 and MCG-803 cells in vitro detected by qPCR. F. Relative expression of PDCD5 in nude mice injected with PITX1 shRNA in vivo.

Fig. 7. Effects of PDCD5 in cell apoptosis in GC cells. A.PDCD5 was enhanced expression in AGS and BGC-823 cells. B. Flow cytometry analysis of cell apoptosis in AGS and BGC-823 cells transfected with pReceiver-M13 and pReceiver - M 13 - P D C D 5 plasmids. The apoptosis rate was calculated and depicted in a bar chart. The values indicate the mean \pm SD. for three separate experiments
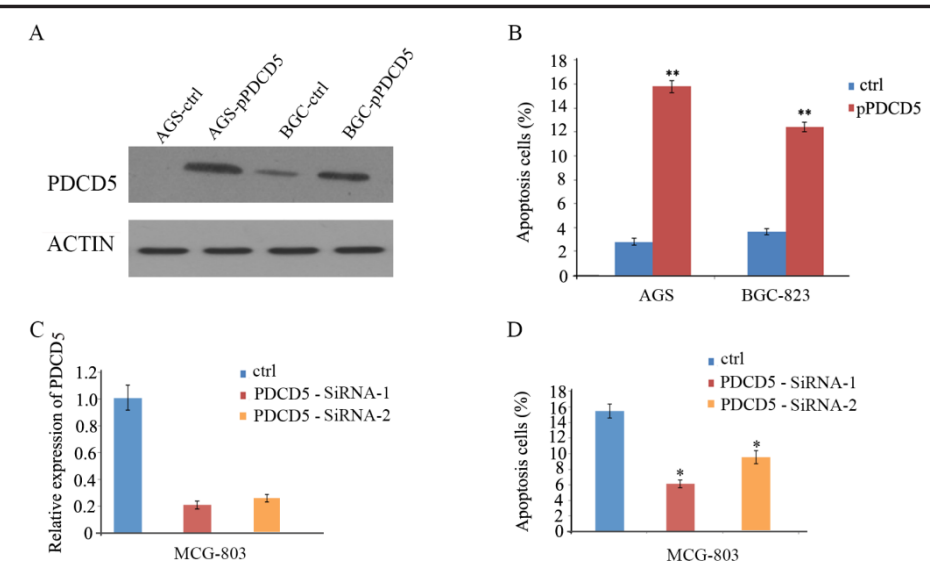

(Student t-test, ${ }^{* *} \mathrm{P}<0.01$ ). C. PDCD5 was knocked down in MCG-803 cells by siRNAs. D. Flow cytometry analysis of cell apoptosis in MCG-803 cells transfected with PDCD5 SiRNA-1 or SiRNA-2 and controls. $* \mathrm{P}<0.05,{ }^{* *} \mathrm{P}<0.01$.

\section{PITX1 expression is regulated by $m i R-19 a-3 p$}

In order to understand the regulatory mechanism of PITX1 in GC, we screened for a candidate miRNA that might bind to the 3'UTR of the PITX1 mRNA using TargetScan, PicTar, and miRanda software. miR-19a-3p includes a seed sequence at the $5^{\prime}$ end that is complementary to a sequence within the 3'UTR region of PITX1 mRNA (nucleotides 912919). Moreover, the PITX1 mRNA regions complementary to this 8-nt seed sequence of miR-19a-3p are highly conserved among different species (Fig. 8A). To further validate the putative sites of the miR-19b initial binding within the 3'UTR of PITX1 mRNA, we generated KARGER 
Fig. 8.. PITX1 expression was regulated by miR-19a-3p. A. Sequence alignment of the miR-19a-3p nucleotide sites with the 3'UTR of PITX1 mRNA of different species. The sequences of miR-19a-3p that were complementary to PITX1 3' UTR mRNA sequences were shown in red. B. Alignment of the miR-19a-3p nucleotide sequence with the wild type and mutated target sites of the PITX1 mRNA 3'UTR region (PITX1 3'UTR and PITX1 3' UTR mutant respectively) that were used to construct luciferase reporter plasmids. C. Dual luciferase reporter assay analysis of the effect of miR-19a-3p expression on PITX1 3'UTR in AGS cells. * $\mathrm{P}<0.05$. D. qRT-PCR and/or western blot analysis of PITX1 mRNA/protein expression in miR-19a-3p up-regulation. ${ }^{*} \mathrm{P}<0.05$.

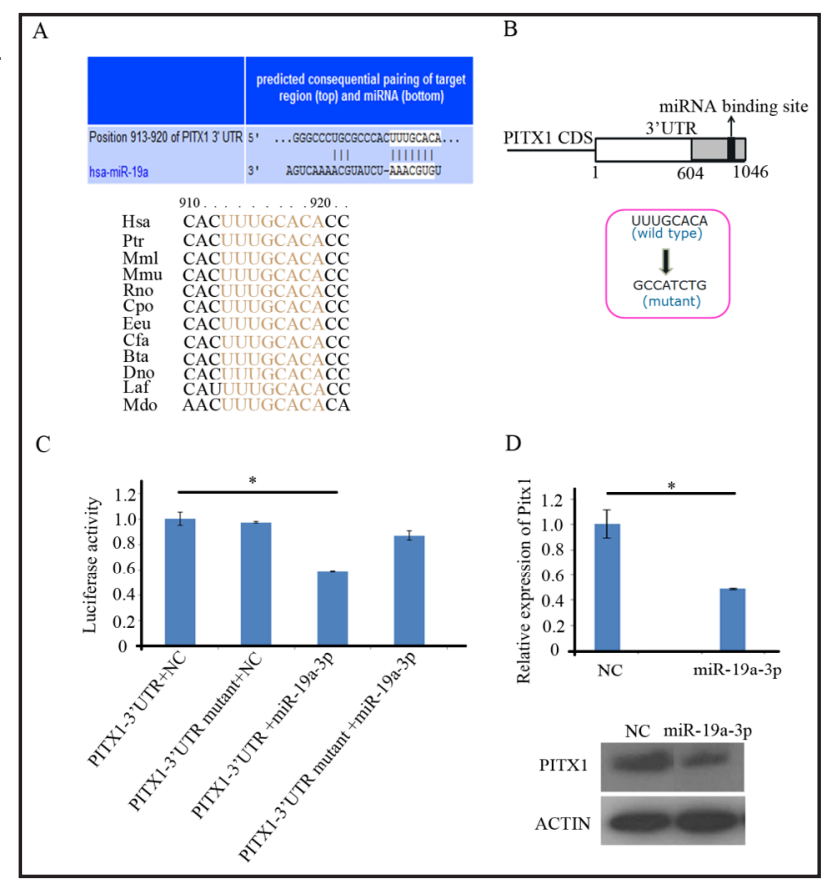

full-length PITX1-3'UTR luciferase reporter constructs that contained the predicted, wildtype (wt) miR-19a-3p binding sites (PITX1-3'UTR) or a mutant site (PITX1-3'UTR mutant) (Fig. 8B). A dual luciferase reporter assay confirmed the direct interaction of miR-19a-3p and PITX1 3'UTR in AGS cells (Fig. 8C). Transient overexpression of miR-19a-3p significantly decreased PITX1 mRNA and protein expression compared with control cells (Fig. 8D). These data provide evidence that miR-19a-3p repressed PITX1 transcription and translation through specific binding to the PITX1 mRNA sequence.

\section{Discussion}

Although PITX1 was first identified to participate in limb morphogenesis and pituitary development [30], it was also found to have a potential suppressive role in the progression of several cancers, such as colorectal carcinoma [18, 23], hepatocellular carcinoma [31], lung cancer [22], and GC [24]. In normal human tissues, PITX1 expression in gastric normal mucosa is higher than in other digestive system tissues, except the esophageal mucosa(Genotype-Tissue Expression Project), indicating that PITX1 may play an important role in maintenance of the normal gastrointestinal tract. Moreover, our data suggested that PITX1 showed decreased expression in GC tissues and GC cell lines. The potential molecular mechanism of PITX1, particularly how it functions as a transcription factor to regulate gene expression during tumorigenesis, is still poorly understood. In the present study, we revealed how PITX1 acts as a transcriptional activator of apoptosis-related genes.

We found that PITX1 significantly suppressed GC cell proliferation when transiently overexpressed in the GC cell lines AGS and BGC-803. In contrast, cell proliferation ability was improved in MCG-803 cells with PITX1 shRNA. Furthermore, we found that ectopic expression of PITX1 significantly increased the percentage of AGS and BGC-823 cells in the G0/G1 phase, whereas knockdown of PITX1 significantly reduced the percentage of cells in the G0/G1 phase. These data indicated that PITX1 blocked the cell cycle at the G1/S transition. Meanwhile, overexpression of PITX1 significantly increased cell apoptosis by increasing cleaved caspase-3 and cleaved caspase-9. In an in vivo assay, knockdown of PITX1 significantly promoted neoplastic growth (both volume and weight). As expected, the size of the tumor in mice had a negative correlation with the PITX1 expression level in vivo. 
In a previous study, PITX1 was identified as a suppressor of RAS and found to inhibit tumor promotion [18]. Evidence suggests that unstable PITX1 weakens the transcriptional activity for p120RasGAP, targeting the PITX1-p120RasGAP axis and providing a new therapy for patients with hepatocellular carcinoma [31]. In order to uncover how PITX1 acts as a transcription factor to regulate and modulate GC cell proliferation, we carried out PITX1 ChIP-seq and identified the direct transcriptional targets of PITX1. The genes regulated by PITX1 mainly participated in cell growth and cell apoptosis, which is consistent with its biological function in GC cell lines. Via in-depth analysis of PITX1 binding with tumor-related genes and their function in gastric carcinogenesis, PDCD5 was selected as a candidate gene for further validation. We found that PITX1 regulated PDCD5 gene transcription by directly binding to the PDCD5 promoter and promoted cell apoptosis in GC. In light of these findings, it is clear that PITX1 acts as a classical transcription factor and regulates gene expression during gastric carcinogenesis.

However, the precise molecular mechanism underlying PITX1 regulation of expression remains unclear. Previous studies showed that miRNAs play vital roles in GC carcinogenesis [32-34]. In addition, miR-19b regulates hTERT mRNA expression by targeting PITX1 mRNA in melanoma cells [26], and enhanced miR-886-3p expression regulates cell migration, proliferation, and apoptosis by targeting PITX1 in clear cell renal cell carcinoma [35]. In this work, we found that miR-19a-3p directly targeted PITX1 mRNA and led to a decreased expression of PITX1 mRNA and protein. To our knowledge, the present study is the first to provide evidence that PITX1 expression is modulated through miR-19a-3p in GC. miR-19a is frequently overexpressed, promotes cell proliferation and the epithelial to mesenchymal transition, and inhibits cell apoptosis in lung carcinoma [36, 37], osteosarcoma stem cells [38], colorectal cancer [39-42], cell renal cell carcinoma [43], oral squamous cell carcinoma [44], hepatocellular carcinoma cells [45], pancreatic cancer [46], GC [47, 48], cholangiocarcinoma [49], breast cancer [50], bladder cancer [51], medulloblastoma [52], and cervical carcinoma [53]. Our findings are consistent with these data because they provide evidence that miR$19 \mathrm{a}$ is a key regulator of the multistep processes of cancer development. Further studies should analyze the correlation between miR-19a-3p and PITX1 in vivo.

In conclusion, to the best of our knowledge, this is the first report to reveal that PITX1 is a crucial regulator of the apoptosis-related gene PDCD5 and plays a role as a tumor suppressor during gastric carcinogenesis. Decreased expression of PITX1 is associated with poor prognosis in GC patients. Elevated PITX1 expression inhibits cellular proliferation by arresting the cell cycle at the G1/S phase and induces cell apoptosis by targeting the PDCD5 promoter in vitro and in vivo. These data indicate a novel potential therapeutic target for GC. In addition, PITX1 expression is modulated by miR-19a-3p, which also provides a potential approach to GC management.

\section{Acknowledgements}

We thank Dr. Jingfei Chen (Department of Oncology, Nanjing First Hospital, Nanjing Medical University for performing some of the tissue microarray analysis for GC patients). We also thank Mr. Kun Zhang at the 3rd Affiliated Hospital of Harbin Medical University for collecting and evaluating partial GC fresh tissues used in the present study.

This work was supported by the National Natural Science Foundation of China (No.81472548, No. 81672414).

\section{Disclosure Statement}

The authors declare to have no conflicts of interest. 


\section{Cellular Physiology Cell Physiol Biochem 2018;46:2215-2231 \begin{tabular}{c|c|c|} 
DOI: 10.1159/000489590 & O 2018 The Author(s). Published by S. Karger AG, Basel \\
www.karger.com/cpb
\end{tabular} and Biochemistry \\ Qiao et al.: PITX1 Modulated by MiR-19a-3p Promotes Gastric Cell Malignancy by Affect-}

ing Transcriptionally Activated PDCD5

\section{References}

1 Lazar DC, Taban S, Cornianu M, Faur A, Goldis A: New advances in targeted gastric cancer treatment. World J Gastroenterol 2016;22:6776-6799.

-2 Peng Z, Li Z, Gao J, Lu M, Gong J, Tang ET, Oliner KS, Hei YJ, Zhou H, Shen L: Tumor MET Expression and Gene Amplification in Chinese Patients with Locally Advanced or Metastatic Gastric or Gastroesophageal Junction Cancer. Mol Cancer Ther 2015;14:2634-2641.

-3 Kang YK, Muro K, Ryu MH, Yasui H, Nishina T, Ryoo BY, Kamiya Y, Akinaga S, Boku N: A phase II trial of a selective c-Met inhibitor tivantinib (ARQ 197) monotherapy as a second- or third-line therapy in the patients with metastatic gastric cancer. Invest New Drugs 2014;32:355-361.

4 Yu S, Yu Y, Zhao N, Cui J, Li W, Liu T: C-Met as a prognostic marker in gastric cancer: a systematic review and meta-analysis. PLoS One 2013;8:e79137.

-5 Nakajima M, Sawada H, Yamada Y, Watanabe A, Tatsumi M, Yamashita J, Matsuda M, Sakaguchi T, Hirao T, Nakano H: The prognostic significance of amplification and overexpression of c-met and c-erb B-2 in human gastric carcinomas. Cancer 1999;85:1894-1902.

6 Sukawa Y, Yamamoto H, Nosho K, Ito M, Igarashi H, Naito T, Mitsuhashi K, Matsunaga Y, Takahashi T, Mikami M, Adachi Y, Suzuki H, Shinomura Y: HER2 expression and PI3K-Akt pathway alterations in gastric cancer. Digestion 2014;89:12-17.

7 Shi J, Yao D, Liu W, Wang N, Lv H, Zhang G, Ji M, Xu L, He N, Shi B, Hou P: Highly frequent PIK3CA amplification is associated with poor prognosis in gastric cancer. BMC Cancer 2012;12:50.

-8 Samuels Y, Wang Z, Bardelli A, Silliman N, Ptak J, Szabo S, Yan H, Gazdar A, Powell SM, Riggins GJ, Willson JK, Markowitz S, Kinzler KW, Vogelstein B, Velculescu VE: High frequency of mutations of the PIK3CA gene in human cancers. Science 2004;304:554.

-9 Jackson CB, Giraud AS: STAT3 as a prognostic marker in human gastric cancer. J Gastroenterol Hepatol 2009;24:505-507.

10 Han JC, Zhang KL, Chen XY, Jiang HF, Kong QY, Sun Y, Wu ML, Huang L, Li H, Liu J: Expression of seven gastric cancer-associated genes and its relevance for Wnt, NF-kappaB and Stat3 signaling. Apmis 2007;115:13311343.

11 Comprehensive molecular characterization of gastric adenocarcinoma. Nature 2014;513:202-209.

12 Lamonerie T, Tremblay JJ, Lanctot C, Therrien M, Gauthier Y, Drouin J: Ptx1, a bicoid-related homeo box transcription factor involved in transcription of the pro-opiomelanocortin gene. Genes Dev 1996;10:12841295.

13 Qi DL, Ohhira T, Fujisaki C, Inoue T, Ohta T, Osaki M, Ohshiro E, Seko T, Aoki S, Oshimura M, Kugoh H: Identification of PITX1 as a TERT suppressor gene located on human chromosome 5. Mol Cell Biol 2011;31:1624-1636.

14 Poulin G, Lebel M, Chamberland M, Paradis FW, Drouin J: Specific protein-protein interaction between basic helix-loop-helix transcription factors and homeoproteins of the Pitx family. Mol Cell Biol 2000;20:48264837.

15 Yamamizu K, Sharov AA, Piao Y, Amano M, Yu H, Nishiyama A, Dudekula DB, Schlessinger D, Ko MS: Generation and gene expression profiling of 48 transcription-factor-inducible mouse embryonic stem cell lines. Sci Rep 2016;6:25667.

16 Jayewickreme CD, Shivdasani RA: Control of stomach smooth muscle development and intestinal rotation by transcription factor BARX1. Dev Biol 2015;405:21-32.

17 Liu DX, Lobie PE: Transcriptional activation of p53 by Pitx1 Cell Death Differ 2007;14:1893-1907.

-18 Kolfschoten IG, van Leeuwen B, Berns K, Mullenders J, Beijersbergen RL, Bernards R, Voorhoeve PM, Agami R: A genetic screen identifies PITX1 as a suppressor of RAS activity and tumorigenicity. Cell 2005;121:849858.

19 Liborio TN, Acquafreda T, Matizonkas-Antonio LF, Silva-Valenzuela MG, Ferraz AR, Nunes FD: In situ hybridization detection of homeobox genes reveals distinct expression patterns in oral squamous cell carcinomas. Histopathology 2011;58:225-233.

20 Osaki M, Chinen H, Yoshida Y, Ohhira T, Sunamura N, Yamamoto O, Ito H, Oshimura M, Kugoh H: Decreased PITX1 gene expression in human cutaneous malignant melanoma and its clinicopathological significance. Eur J Dermatol 2013;23:344-349. 


\section{Cellular Physiology Cell Physiol Biochem 2018;46:2215-2231 \begin{tabular}{c|c|c|} 
DOI: 10.1159/000489590 & Cond Biochemistry & 2018 The Author(s). Published by S. Karger AG, Basel \\
www.karger.com/cpb
\end{tabular} and Biochemistry \\ Qiao et al.: PITX1 Modulated by MiR-19a-3p Promotes Gastric Cell Malignancy by Affect-}

ing Transcriptionally Activated PDCD5

-21 Lord RV, Brabender J, Wickramasinghe K, DeMeester SR, Holscher A, Schneider PM, Danenberg PV, DeMeester TR: Increased CDX2 and decreased PITX1 homeobox gene expression in Barrett's esophagus and Barrett's-associated adenocarcinoma. Surgery 2005;138:924-931.

-22 Chen Y, Knosel T, Ye F, Pacyna-Gengelbach M, Deutschmann N, Petersen I: Decreased PITX1 homeobox gene expression in human lung cancer. Lung Cancer 2007;55:287-294.

-23 Knosel T, Chen Y, Hotovy S, Settmacher U, Altendorf-Hofmann A, Petersen I: Loss of desmocollin 1-3 and homeobox genes PITX1 and CDX2 are associated with tumor progression and survival in colorectal carcinoma. Int J Colorectal Dis 2012;27:1391-1399.

24 Chen YN, Chen H, Xu Y, Zhang X, Luo Y: Expression of pituitary homeobox 1 gene in human gastric carcinogenesis and its clinicopathological significance. World J Gastroenterol 2008;14:292-297.

-25 Quentien MH, Manfroid I, Moncet D, Gunz G, Muller M, Grino M, Enjalbert A, Pellegrini I: Pitx factors are involved in basal and hormone-regulated activity of the human prolactin promoter. J Biol Chem 2002;277:44408-44416.

26 Ohira T, Naohiro S, Nakayama Y, Osaki M, Okada F, Oshimura M, Kugoh H: miR-19b regulates hTERT mRNA expression through targeting PITX1 mRNA in melanoma cells. Sci Rep 2015;5:8201.

27 Grimes HL, Chan TO, Zweidler-McKay PA, Tong B, Tsichlis PN: The Gfi-1 proto-oncoprotein contains a novel transcriptional repressor domain, SNAG, and inhibits G1 arrest induced by interleukin-2 withdrawal. Mol Cell Biol 1996;16:6263-6272.

28 Xu HY, Chen ZW, Pan YM, Fan L, Guan J, Lu YY: Transfection of PDCD5 effect on the biological behavior of tumor cells and sensitized gastric cancer cells to cisplatin-induced apoptosis. Dig Dis Sci 2012;57:18471856.

29 Yang YH, Zhao M, Li WM, Lu YY, Chen YY, Kang B, Lu YY: Expression of programmed cell death 5 gene involves in regulation of apoptosis in gastric tumor cells. Apoptosis 2006;11:993-1001.

-30 Szeto DP, Rodriguez-Esteban C, Ryan AK, O'Connell SM, Liu F, Kioussi C, Gleiberman AS, IzpisuaBelmonte JC, Rosenfeld MG: Role of the Bicoid-related homeodomain factor Pitx1 in specifying hindlimb morphogenesis and pituitary development. Genes Dev 1999;13:484-494.

31 Tai WT, Chen YL, Chu PY, Chen LJ, Hung MH, Shiau CW, Huang JW, Tsai MH, Chen KF: Protein tyrosine phosphatase 1B dephosphorylates PITX1 and regulates p120RasGAP in hepatocellular carcinoma. Hepatology 2016;63:1528-1543.

-32 Si Y, Zhang H, Ning T, Bai M, Wang Y, Yang H, Wang X, Li J, Ying G, Ba Y: miR-26a/b Inhibit Tumor Growth and Angiogenesis by Targeting the HGF-VEGF Axis in Gastric Carcinoma. Cell Physiol Biochem 2017;42:1670-1683.

33 Guo B, Zhao Z, Wang Z, Li Q, Wang X, Wang W, Song T, Huang C: MicroRNA-302b-3p Suppresses Cell Proliferation Through AKT Pathway by Targeting IGF-1R in Human Gastric Cancer. Cell Physiol Biochem 2017;42:1701-1711.

34 Li S, Zhang H, Ning T, Wang X, Liu R, Yang H, Han Y, Deng T, Zhou L, Zhang L, Bai M, Wang X, Ge S, Ying G, Ba Y: MiR-520b/e Regulates Proliferation and Migration by Simultaneously Targeting EGFR in Gastric Cancer. Cell Physiol Biochem 2016;40:1303-1315.

-35 Yu Z, Chen D, Su Z, Li Y, Yu W, Zhang Q Yang L, Li C, Yang S, Ni L, Gui Y, Mao Z, Lai Y: miR8863p upregulation in clear cell renal cell carcinoma regulates cell migration, proliferation and apoptosis by targeting PITX1Int J Mol Med 2014;34:1409-1416.

-36 Gu Y, Liu S, Zhang X, Chen G, Liang H, Yu M, Liao Z, Zhou Y, Zhang CY, Wang T, Wang C, Zhang J, Chen X: Oncogenic miR-19a and miR-19b co-regulate tumor suppressor MTUS1 to promote cell proliferation and migration in lung cancer. Protein Cell 2017;8:455-466.

-37 Li J, Yang S, Yan W, Yang J, Qin YJ, Lin XL, Xie RY, Wang SC, Jin W, Gao F, Shi JW, Zhao WT, Jia JS, Shen HF, Ke JR, Liu B, Zhao YQ Huang WH, Yao KT, Li DJ, Xiao D: MicroRNA-19 triggers epithelial-mesenchymal transition of lung cancer cells accompanied by growth inhibition. Lab Invest 2015;95:1056-1070.

-38 Zhao D, Chen Y, Chen S, Zheng C, Hu J, Luo S: MiR-19a regulates the cell growth and apoptosis of osteosarcoma stem cells by targeting PTEN. Tumour Biol 2017;39:1010428317705341.

-39 Liu Y, Liu R, Yang F, Cheng R, Chen X, Cui S, Gu Y, Sun W, You C, Liu Z, Sun F, Wang Y, Fu Z, Ye C, Zhang C, Li J, Chen X: miR-19a promotes colorectal cancer proliferation and migration by targeting TIA1 Mol Cancer 2017;16:53. 


\section{Cellular Physiology Cell Physiol Biochem 2018;46:2215-2231

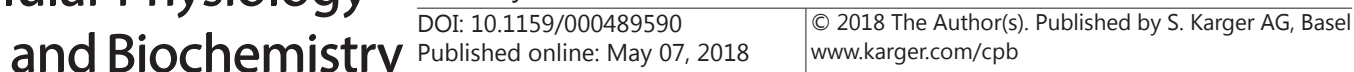 \\ Qiao et al.: PITX1 Modulated by MiR-19a-3p Promotes Gastric Cell Malignancy by Affect-}

ing Transcriptionally Activated PDCD5

40 Li Y, Lauriola M, Kim D, Francesconi M, D'Uva G, Shibata D, Malafa MP, Yeatman TJ, Coppola D, Solmi R, Cheng JQ: Adenomatous polyposis coli (APC) regulates miR17-92 cluster through beta-catenin pathway in colorectal cancer. Oncogene 2016;35:4558-4568.

41 Huang L, Wang X, Wen C, Yang X, Song M, Chen J, Wang C, Zhang B, Wang L, Iwamoto A, Wang J, Liu H: Hsa-miR-19a is associated with lymph metastasis and mediates the TNF-alpha induced epithelial-tomesenchymal transition in colorectal cancer. Sci Rep 2015;5:13350.

42 Cellura D, Pickard K, Quaratino S, Parker H, Strefford JC, Thomas GJ, Mitter R, Mirnezami AH, Peake NJ: miR19-Mediated Inhibition of Transglutaminase-2 Leads to Enhanced Invasion and Metastasis in Colorectal Cancer. Mol Cancer Res 2015;13:1095-1105.

43 Ma Q, Peng Z, Wang L, Li Y, Wang K, Zheng J, Liang Z, Liu T: miR-19a correlates with poor prognosis of clear cell renal cell carcinoma patients via promoting cell proliferation and suppressing PTEN/SMAD4 expression. Int J Oncol 2016;49:2589-2599.

44 Christopher AF, Gupta M, Bansal P: Micronome revealed miR-19a/b as key regulator of SOCS3 during cancer related inflammation of oral squamous cell carcinoma. Gene 2016;594:30-40.

45 Baik SH, Lee J, Lee YS, Jang JY, Kim CW: ANT2 shRNA downregulates miR-19a and miR-96 through the PI3K/Akt pathway and suppresses tumor growth in hepatocellular carcinoma cells. Exp Mol Med 2016;48:e222.

46 Tan Y, Yin H, Zhang H, Fang J, Zheng W, Li D, Li Y, Cao W, Sun C, Liang Y, Zeng J, Zou H, Fu W, Yang X: Sp1-driven up-regulation of miR-19a decreases RHOB and promotes pancreatic cancer. Oncotarget 2015;6:17391-17403.

47 Lu WD, Zuo Y, Xu Z, Zhang M: MiR-19a promotes epithelial-mesenchymal transition through PI3K/AKT pathway in gastric cancer. World J Gastroenterol 2015;21:4564-4573.

-48 Wu Q, Yang Z, An Y, Hu H, Yin J, Zhang P, Nie Y, Wu K, Shi Y, Fan D: MiR-19a/b modulate the metastasis of gastric cancer cells by targeting the tumour suppressor MXD1 Cell Death Dis 2014;5:e1144.

-49 Zhu H, Han C, Lu D, Wu T: miR-17-92 cluster promotes cholangiocarcinoma growth: evidence for PTEN as downstream target and IL-6/Stat3 as upstream activator. Am J Pathol 2014;184:2828-2839.

50 Sochor M, Basova P, Pesta M, Dusilkova N, Bartos J, Burda P, Pospisil V, Stopka T: Oncogenic microRNAs: miR-155, miR-19a, miR-181b, and miR-24 enable monitoring of early breast cancer in serum. BMC Cancer 2014;14:448.

51 Feng Y, Liu J, Kang Y, He Y, Liang B, Yang P, Yu Z: miR-19a acts as an oncogenic microRNA and is upregulated in bladder cancer. J Exp Clin Cancer Res 2014;33:67.

52 Murphy BL, Obad S, Bihannic L, Ayrault O, Zindy F, Kauppinen S, Roussel MF: Silencing of the miR-17 92 cluster family inhibits medulloblastoma progression. Cancer Res 2013;73:7068-7078.

53 Xu XM, Wang XB, Chen MM, Liu T, Li YX, Jia WH, Liu M, Li X, Tang H: MicroRNA-19a and -19b regulate cervical carcinoma cell proliferation and invasion by targeting CUL5. Cancer Lett 2012;322:148-158. 